\title{
USO E OCUPAÇÃO DAS APPS EM ÁREAS DE FUNDO DE VALE NO PERÍMETRO URBANO DE LONDRINA-PR, UTILIZANDO IMAGEM DE ALTA RESOLUÇÃO
}

\section{Use and occupation of the APPs in bottom of valley areas in the urban perimeter of Londrina-PR, using high resolution image}

\author{
Kleber TRABAQUINI ${ }^{1}$ \\ Mariane Mayumi Garcia TAKEDA ${ }^{2}$ \\ Renata ROMAGNOLLI ${ }^{3}$ \\ Mirian Vizintim Fernandes BARROS ${ }^{4}$
}

\begin{abstract}
RESUMO
$\mathrm{Na}$ cidade de Londrina existem vários conflitos de ordem social e ambiental decorrente de seu processo de ocupação e rápido crescimento. Entre estes conflitos, estão as ocupações irregulares em fundos de vale. Neste sentido, este estudo teve como objetivo mapear as Áreas de Preservação Permanente - APPs de fundo de vale utilizando imagens de alta resolução espacial do satélite Quickbird e técnicas Geoprocessamento por meio do software SPRING. Estas ferramentas propiciaram a análise das áreas de APPs, onde se constatou visualmente, através da imagem orbital e dos trabalhos de campo, que em várias áreas a legislação pertinente à proteção não está sendo respeitada, ou seja, diversas áreas de fundo de vale estão sendo ocupadas por usos irregulares como mostra o presente trabalho.
\end{abstract}

Palavras-chave: Área de Preservação Permanente; Quickbird; Legislação; Geoprocessamento; Sensoriamento Remoto.

\begin{abstract}
In the city of Londrina there are several conflicts of social and environmental order due to their process of occupation and rapid growth. Among these conflicts, there is an illegal occupation in bottom of valley areas, this paper aims to evaluate the permanent bottom valley areas preservation, using high spatial resolution images from the satellite Quickbird and techniques of Geoprocessing and Remote Sensing using the SPRING software. These tools had propitiated the analysis of the areas of APPs, where if it evidenced visually, through the orbital image and of the works of field, that in some areas the pertinent legislation to the protection is not being respected, that is, diverse areas of deep of valley are being busy for irregular uses as it shows the present work.
\end{abstract}

Keywords: Permanent Preservation Area; Quickbird; Legislation; Geoprocessing; Remote Sensing.

\footnotetext{
2 Geógrafa, mestranda em Geografia Dinâmica Espaço Ambiental, Universidade Estadual de Londrina - UEL. Londrina/Pr. E-mail: mariane.takeda@gmail.com

3 Arquiteta, mestranda em Engenharia de Edificações e Saneamento, Universidade Estadual de Londrina - UEL. Londrina/Pr. Email: reromgnoli@hotmail.com

4 Geógrafa, doutora em Geografia Física pela USP, Profa. Dra. Do Departamento de Geociências da Universidade Estadual de Londrina - UEL. Londrina/Pr. Email: mirianvizintim@hotmail.com
} inpe.br

1 Eng. Agrônomo, doutorando em Sensoriamento Remoto, Instituto Nacional de Pesquisas Espaciais - INPE. E-mail: kleber@dsr. 


\section{INTRODUÇÃO}

Fundado em 1929 e emancipado em 12 de dezembro de 1934, o Município de Londrina apresenta-se jovem para o seu rápido desenvolvimento demonstrado ao longo das décadas. A princípio, a expansão da cafeicultura, do Estado de São Paulo para o Norte do Paraná, trouxe muitas famílias para se instalarem no município. Na década de 1970, com a mecanização da agricultura, grande parte dessas famílias foram impulsionadas a mudarem para a cidade, de forma que não houve tempo para um planejamento adequado de ocupação do espaço urbano. Nas décadas seguintes, em busca de qualificação profissional, bons negócios e mais opções de atividades sociais foram surgindo e outros grandes contingentes de pessoas passaram a residir nesta cidade.

Atualmente, áreas impróprias para a urbanização têm sido ocupadas, incluindo as Áreas de Preservação Permanente (APPs), que são segundo Barros et al. (2003), aquelas que margeiam os cursos hídricos, como rios, nascentes, lagos e represas, além de encostas com declividade superiores a $45^{\circ}$, topo de morro e qualquer outra quando declarada pelo poder público.

A preservação da mata ciliar ou vegetação ripária nas APPs de fundo de vale é de suma importância já que é a base para o equilíbrio natural do ecossistema. Popularmente mais conhecida como mata ciliar, a vegetação ripária se desenvolve ao longo dos rios, mananciais, reservatórios e demais corpos d'água e está entre os ecossistemas mais perturbados pela ação antrópica. "Funciona como reguladora do fluxo de água, sedimentos e nutrientes entre os ecossistemas aquático e terrestre, reduzindo o assoreamento e auxiliando na manutenção da qualidade da água" (MENDONÇA; BARROS, 2002). Segundo Zanini (1998), esta vegetação atua sobre alguns dos elementos climáticos contribuindo para o controle da radiação solar, temperatura e umidade do ar, velocidade dos ventos e a ação das chuvas, além de reduzir a propagação de ruídos.

Legalmente, a vegetação ripária faz parte da Área de Preservação Permanente, na qual é vedado o corte de vegetação nativa ou qualquer outra forma de exploração definida pelo Código Florestal, Lei Federal $n^{\circ}$. 4.771/65. Devendo ser respeitadas as faixas marginais ao longo das margens dos rios, tendo estas larguras variáveis dependendo da largura dos corpos d'água. Ainda neste contexto, a Lei de Crimes Ambientais $\mathrm{n}^{\circ}$. 9.065/98 considera crime destruir ou danificar floresta considerada de preservação permanente, mesmo que em formação, bem como utilizá-la de forma indevida. Conforme estas leis federais citadas, os cursos d'água com menos de 10 metros de largura devem ser margeados em ambos os lados com 30 metros de faixa de preservação e as nascentes ou olhos d'água devem ser circundadas em 50 metros de raio.

Contudo, outro instrumento legal de grande importância na proteção do meio ambiente em áreas urbanas é o Plano Diretor do Município, instituído pela Lei $n^{\circ}$. 7.483/98, que traça diretrizes gerais para o planejamento global da cidade e dita normas para a proteção dos fundos de vale. Segundo esta lei, no município de Londrina deverão ser preservadas as áreas ao longo das margens dos corpos hídricos, numa largura de 30 metros de cada lado, tendo estas áreas o objetivo de proteger os corpos d'água, a preservação ambiental e locais com fins de recreação.

Embora existam ferramentas legais que auxiliem na proteção destas áreas, a sociedade continua transformando a paisagem das áreas de fundo de vale com ocupações irregulares de residências e empresas, dentre outros usos, causando degradações ambientais nestas áreas de preservação. O monitoramento destas irregularidades é de difícil acompanhamento. Para isto, técnicas de geoprocessamento e sensoriamento remoto vêm sendo empregadas, auxiliando os órgãos públicos na aplicação da legislação. Segundo Green (1994), o "Sistema de Informação Geográfica (SIG), tem representado um importante suporte, no que diz respeito ao planejamento e à tomada de decisões quando utilizadas no setor ambiental". A tecnologia do SIG propicia a geração de dados que servem de apoio à tomada de decisões nos mais diferentes projetos que tratam da questão ambiental. A rápida obtenção dos resultados e a possibilidade de uma avaliação integrada de um grande número de variáveis torna vantajoso o uso deste sistema, que ainda "oferece a oportunidade de revisar, incluir e atualizar dados em qualquer etapa do trabalho, transformando-se em uma valiosa ferramenta através da disponibilização futura dos dados gerados" (GUIMARÃES, 2007).

Assim, segundo esse contexto, este estudo teve como objetivo realizar uma avaliação do mapeamento das áreas de APPs, especificamente as localizadas em fundos de vale na área urbana de Londrina-PR, utilizando técnicas de geoprocessamento e sensoriamento remoto em imagens de alta resolução do satélite Quickbird. 


\section{METODOLOGIA DE TRABALHO}

\section{ÁREA DE ESTUDO}

A área urbana do município de Londrina, com $247,65 \mathrm{~km}^{2}$ ou 24.765 ha, está localizada no norte do estado do Paraná e encontra-se entre as latitudes $23^{\circ} 13^{\prime} 58^{\prime \prime}$ e $23^{\circ} 25^{\prime} 09^{\prime \prime}$ e longitudes $51^{\circ} 04^{\prime} 52^{\prime \prime}$ e $51^{\circ}$ 14' 58" (Figura 1). Possui, segundo a classificação de Köppen o clima Cfa, ou seja, clima subtropical, com temperatura média de $18^{\circ} \mathrm{C}$ no mês mais frio e de $22^{\circ}$ $\mathrm{C}$ no mês mais quente, sendo que a vegetação nativa é a Floresta Estacional Semidecidual. Quanto ao relevo, o tipo predominante é o suave ondulado, e está situado no Terceiro Planalto Paranaense, sobre a formação Serra Geral, que é essencialmente constituída por basaltos (rochas básicas), resultando na maioria das vezes na formação de solos argilosos.

Possui uma rica e bem distribuída rede de drenagem, sendo que de maneira geral os rios são de caráter perene, e escoam por sobre o relevo que possui orientação para a margem esquerda do rio Tibagi. Como característica natural, esta cidade conta com a presença de muitas nascentes que dão origem a inúmeros córregos e ribeirões, somente na área urbana encontram-se 84 cursos d'água, o que corresponde a um desafio ímpar em termos de planejamento.

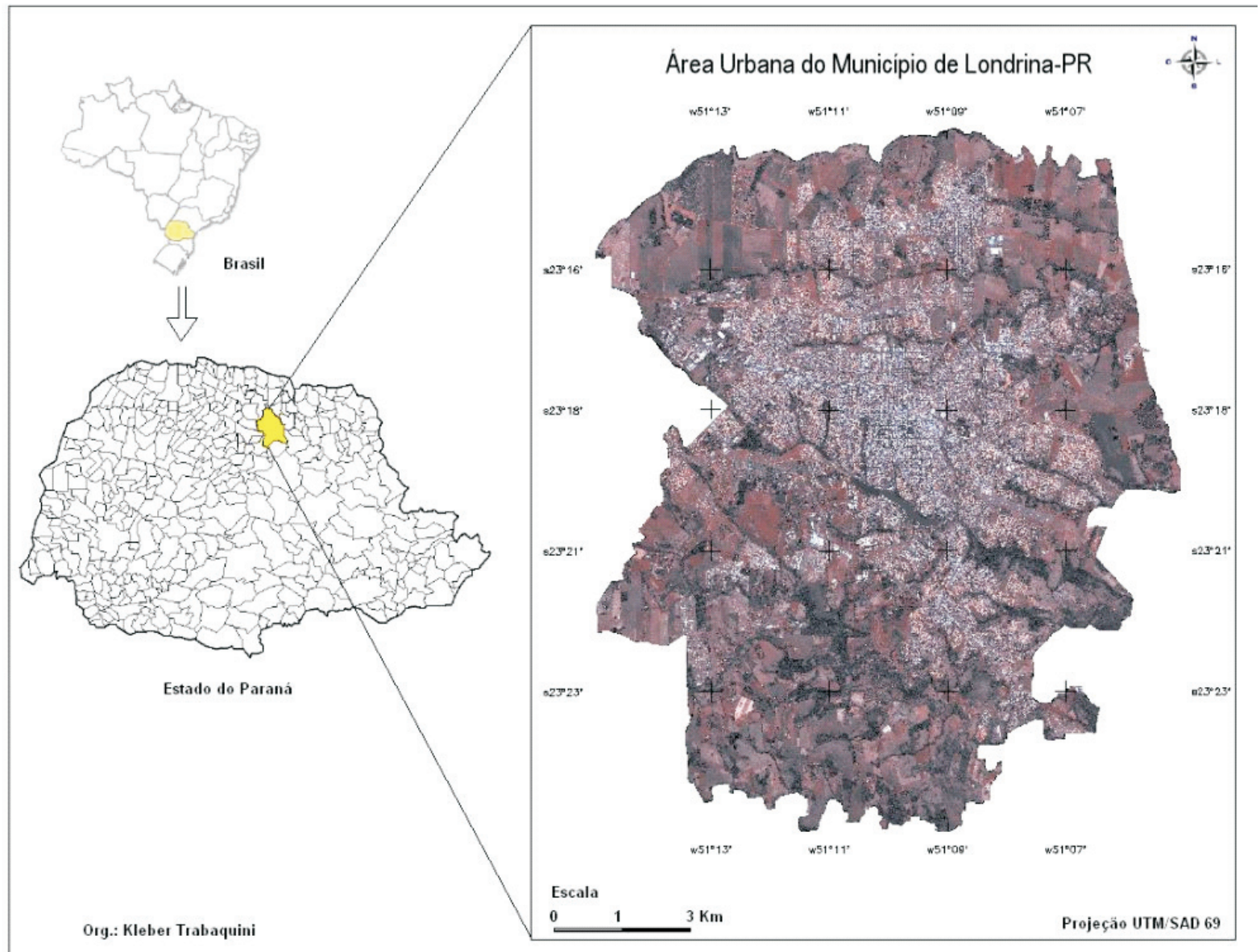

FIGURA 1- LOCALIZAÇÃO DA ÁREA DE ESTUDO. IMAGEM QUICKBIRD EM COMPOSIÇÃO COLORIDA RGB 123, COM DATA DE PASSAGEM EM 22/07/2006 


\section{MATERIAIS}

Foi utilizada a imagem orbital do satélite Quickbird 2 com data de passagem em 22/07/2006, que foi concedida pela Secretaria Municipal do Meio Ambiente (SEMA) de Londrina-Pr ao Departamento de Geociências da Universidade Estadual de Londrina (UEL). As imagens adquiridas para o desenvolvimento deste trabalho já estavam retificadas e georreferenciadas de modo que não foi necessário o georreferenciamento nem o processo de retificação das mesmas para serem inseridas no software SPRING (Sistema de Processamento de Informações Georreferenciadas).

O sensor deste satélite encontra-se a uma altitude de $450 \mathrm{~km}$ com $98^{\circ}$ de inclinação e possui quatro bandas, sendo três multiespectrais com resolução espacial de 2,4 a 2,8 metros e uma pancromática com 0,61 a 0,72 metros, com uma resolução temporal de 1 a 3,5 dias e com uma faixa imageada de $16,5 \mathrm{~km}$ (Tabela 1).

TABELA 1 - PRINCIPAIS CARACTERÍSTICAS DO SENSOR QUICKBIRD

\begin{tabular}{c|c|c|c|c|c}
\hline Sensor & $\begin{array}{c}\text { Bandas } \\
\text { Espectrais }\end{array}$ & $\begin{array}{c}\text { Resolução } \\
\text { Espectral }\end{array}$ & $\begin{array}{c}\text { Resolução } \\
\text { Espacial }\end{array}$ & $\begin{array}{c}\text { Resolução } \\
\text { Temporal }\end{array}$ & $\begin{array}{c}\text { Faixa } \\
\text { Imageada }\end{array}$ \\
\hline \multirow{2}{*}{ Quickbird } & Pancromática & $450-900 \mathrm{~nm}$ & $\begin{array}{c}0,61 \mathrm{a} \\
0,72 \mathrm{~m}\end{array}$ & 1 a 3,5 dias & $\begin{array}{c}16,5 \mathrm{x} \\
16,5 \mathrm{~km}\end{array}$ \\
\cline { 2 - 4 } & $\begin{array}{c}\text { Multiespectral } \\
\text { (visível) }\end{array}$ & $450-520 \mathrm{~nm}$ & \multirow{2}{*}{2,4 a $2,8 \mathrm{~m}$} & & \\
\cline { 3 - 3 } & & $520-600 \mathrm{~nm}$ & & & \\
\cline { 3 - 4 } & & $630-690 \mathrm{~nm}$ & & & \\
\hline
\end{tabular}

FONTE: Embrapa Monitoramento por Satélite.

A base cartográfica de drenagem utilizada foi a de 1991 e o perímetro urbano de 2001, ambos originados do Banco de Dados do IMAP\&P (Grupo Imagens, Paisagens e Personagens) da UEL/CNPq ${ }^{5}$ em formato digital que foi importada para compor a base de dados.

$\mathrm{Na}$ área urbana de Londrina, a rede de drenagem é constituída por cinco principais bacias hidrográficas, nomeadas de acordo com o curso d'água de maior destaque. São elas: bacia do Ribeirão Jacutinga, bacia do Ribeirão Limoeiro, bacia do Ribeirão Cambé (que dá origem aos lagos Igapó), bacia do Ribeirão Cafezal e bacia do Córrego Água das Pedras (Figura 2). Segundo dados da SEMA, estes corpos d'água têm em comum a má qualidade de suas águas, uma vez que praticamente todos têm suas nascentes em áreas urbanas e seus cursos, além do escoamento superficial, recebem o lançamento de águas pluviais e efluentes domésticos e industriais.

O software empregado para a realização das atividades foi o SPRING 4.3, desenvolvido pelo INPE (Instituto Nacional de Pesquisas Espaciais) onde foi criado um banco de dados para a execução deste trabalho. 


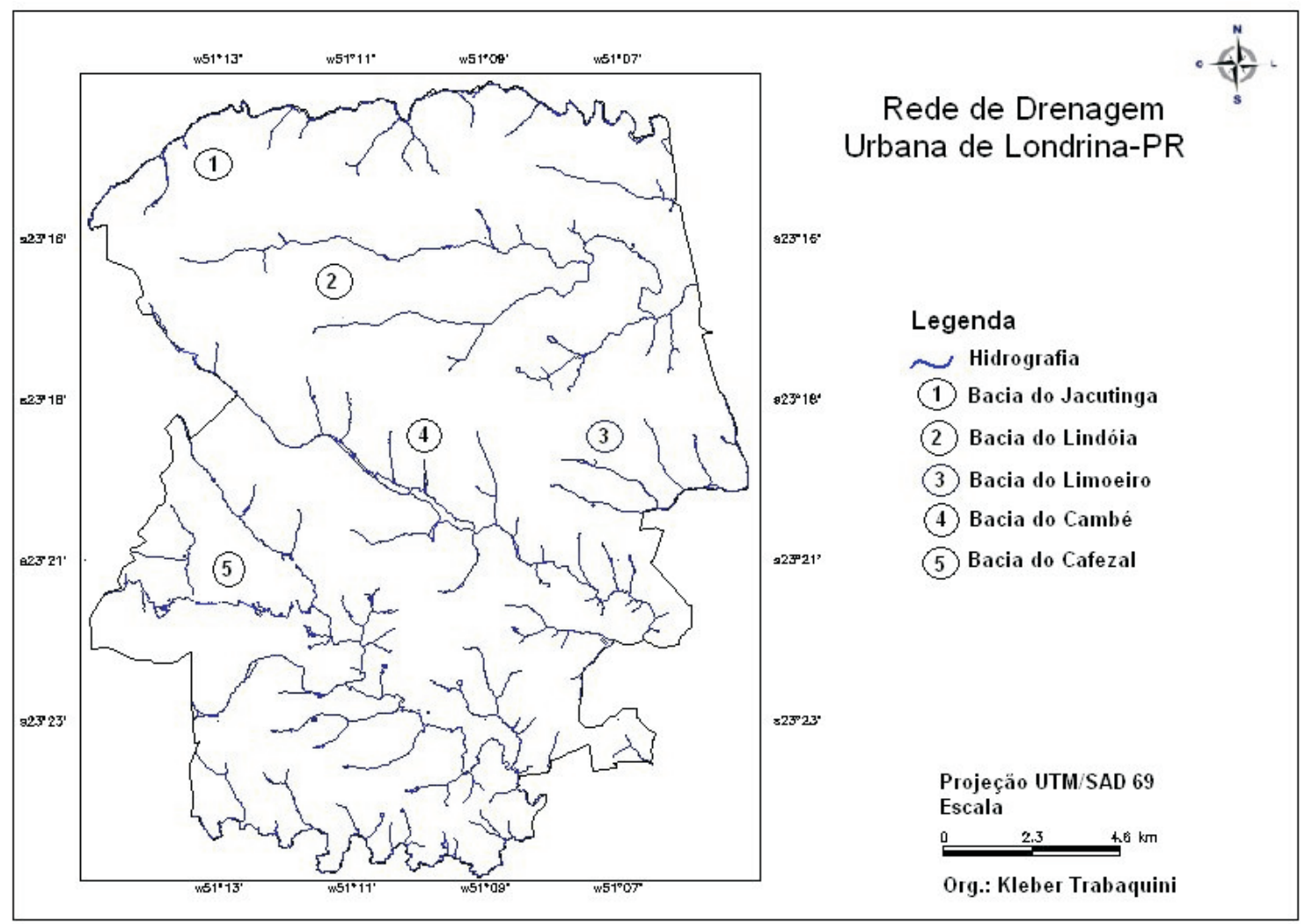

FIGURA 2 - REDE DE DRENAGEM DA ÁREA URBANA DE LONDRINA-PR E SUAS PRINCIPAIS BACIAS HIDROGRÁFICAS

\section{METODOLOGIA}

Primeiramente as bandas multiespectrais foram importadas em formato GeoTIFF para o software SPRING 4.3, para a realização do processo de fusão com a banda pancromática, resultando em uma imagem com resolução espacial de $0,61 \mathrm{~m}$, esta etapa foi importante para que a imagem final tivesse uma resolução de melhor qualidade. Através da composição colorida RGB, composta pelas bandas multiespectrais 1, 2 e 3, foi aplicado um contraste linear para melhor visualização e discriminação entre os objetos estudados.

Após o tratamento da imagem foi elaborado, a partir da carta de drenagem, um mapa de distância mínima de 30 metros para os cursos d'água e 50 para as nascentes em observância à legislação pertinente e ao Código Florestal.

A partir do Mapa de Distâncias e através da edição vetorial disponível no software, foram delimitadas através da classificação visual, seis classes de uso e ocupação do solo dentro da área de APPs de fundo de vale e que são descritas a seguir segundo definições do IBGE (2006).
- $\quad$ - Agrícola: Inclui todas as terras cultivadas, caracterizadas pelo delineamento de áreas cultivadas ou em descanso (solo exposto), podendo compreender qualquer forma de cultivo agrícola seja perene ou temporária.

- $\quad$ - Florestal: mata que nunca sofreu derrubada ou corte, sendo uma remanescente das florestas originais de uma região.

- $\quad$ - Arbórea: refere-se à vegetação com predominância de indivíduos de hábito arbóreo, sendo o sub-bosque normalmente reduzido ou ausente.

- $\quad$ - Capoeira: vegetação secundária que nasce após a derrubada das florestas primárias, e ocorre o predomínio de indivíduos de hábito arbustivo.

- - Rasteira: vegetação normalmente baixa, com predominância de espécies herbáceas, normalmente gramíneas. 
- Urbano: compreendem áreas de uso intensivo, estruturadas por edificações e sistema viário, onde predominam as superfícies artificiais não agrícolas.

A interpretação sobre o uso e ocupação do solo nas áreas de fundo de vale, foi realizada visualmente na tela do computador sobre a imagem Quickbird em composição colorida RGB 123, com escala aproximada de 1:1000. Auxiliada por informações pré-existentes extraídas de fotografias aéreas na escala de 1:8000 de 18/03/1991 fornecida pela Prefeitura Municipal de Londrina, confeccionada pela Aerodata S/A e com posteriores trabalhos de campo para validação da classificação (Figura 3). Em seguida foi realizado o cálculo de área em hectares para todas as classes.
Amostras de imagem Quickbird
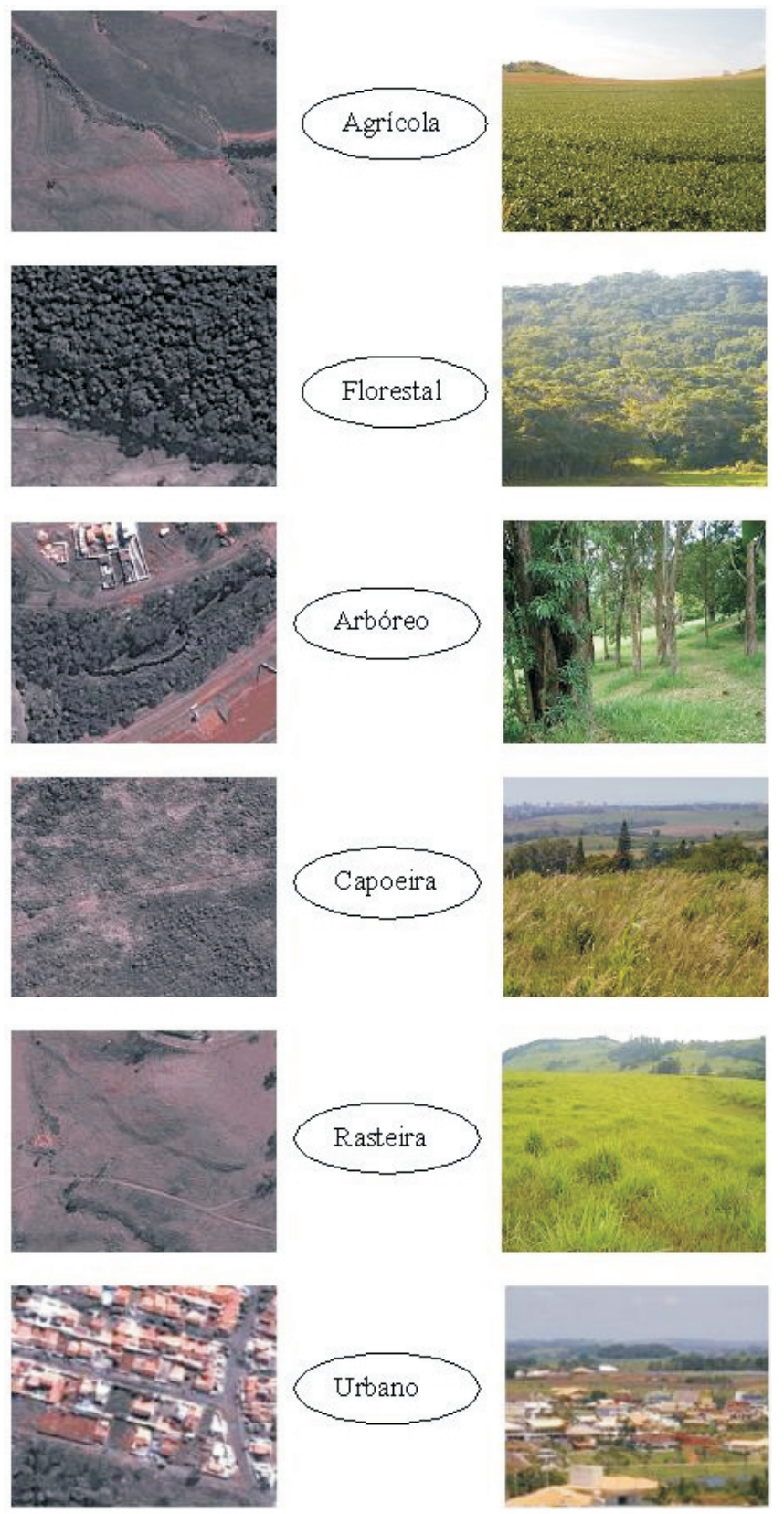

FIGURA 3 - CLASSES DE USO E OCUPAÇÃO DO SOLO UTILIZADAS PARA CLASSIFICAÇÃO, VISUALIZADAS NA IMAGEM QUICKBIRD (COLUNA DA ESQUERDA) E AMOSTRAS REALIZADAS A CAMPO (COLUNA DA DIREITA) 


\section{RESULTADOS E DISCUSSÃO}

A carta de delimitação das APPs dos 84 cursos d'água e suas respectivas nascentes, com 30 metros de margem para os cursos d'água e 50 metros para as nascentes, executada a partir da base cartográfica de drenagem, com o auxilio da ferramenta Mapa de Distâncias disponível no software, foi essencial para gerar os resultados de mapeamento das classes de ocupação. Esta ferramenta propiciou a análise prévia das áreas de APPs, onde se constatou visualmente através da imagem orbital e dos trabalhos de campo, que em várias áreas, a legislação pertinente à proteção não está sendo respeitada, ou seja, diversas áreas de fundo de vale estão sendo ocupadas por usos irregulares. Segundo estudos desenvolvidos por Barros (1998) e Zanini (1998), mais da metade dos fundos de vale da cidade de Londrina encontram-se desprovidos de vegetação. No presente estudo encontrou-se situação semelhante, sendo observado que somente uma pequena parte dos fundos de vale da cidade apresenta cobertura vegetal nativa.

A partir da interpretação da imagem em composição colorida RGB 123, foram estabelecidas as classes de vegetação, resultando na Carta de Uso e Ocupação dos Fundos de Vale da Área Urbana de Londrina (Figura 4). A resolução espacial de 0,61 metros e espectral do sensor Quickbird favoreceram a identificação das diversas formas de ocupação dos fundos de vale, possibilitando diferenciar mais facilmente as classes definidas, consequentemente permitindo desta forma aperfeiçoar os resultados desta pesquisa.

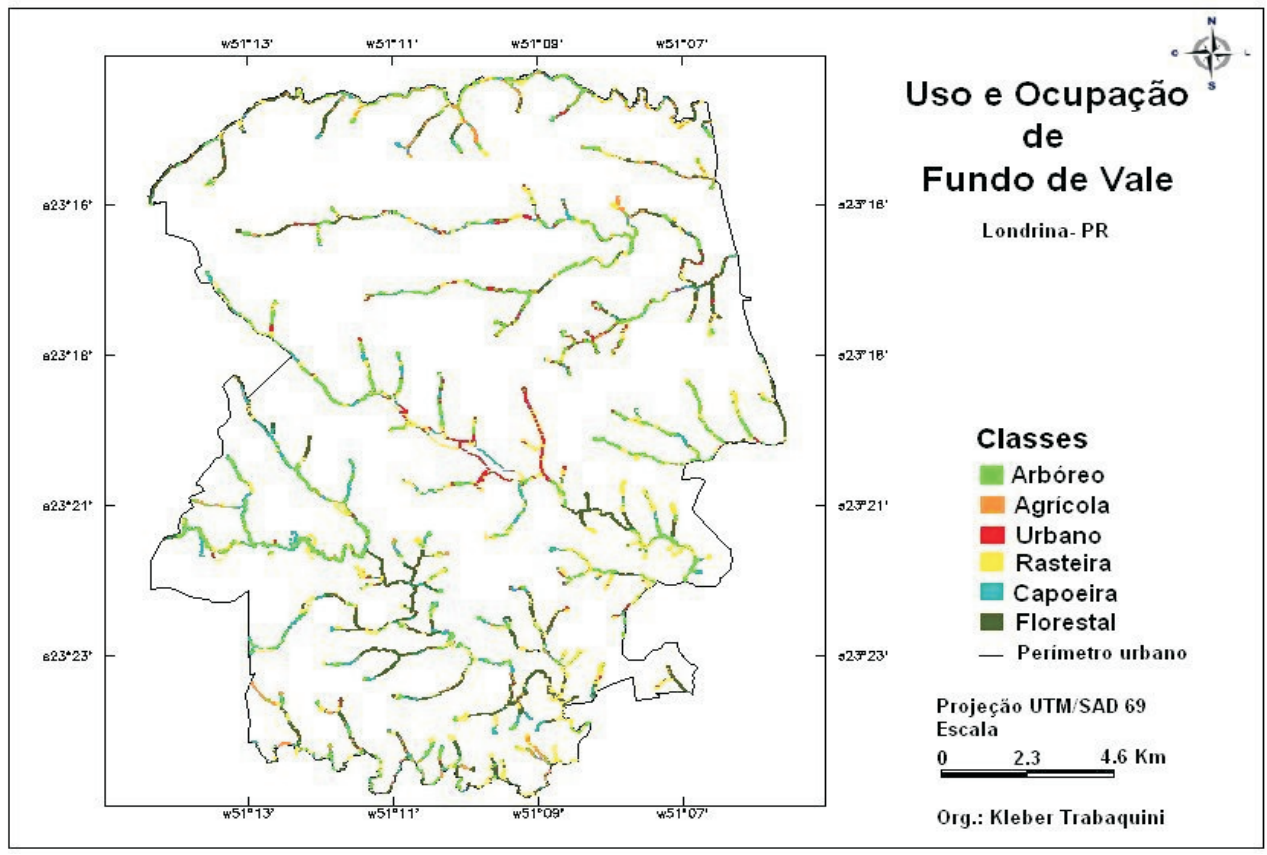

FIGURA 4 - CARTA COM AS CLASSES DE USO E OCUPAÇÃO DOS FUNDOS DE VALE DA ÁREA URBANA DE LONDRINA-PR

A partir dos dados contidos na tabela 2, podemos verificar que a área urbana de Londrina, com 24.765 ha, possui um total de 1.478 ha de APPs somente em fundo de vale, o que corresponde à aproximadamente $6 \%$ da área urbana deste município. Para Pellegrino (2000), os fundos de vale são de extrema importância, pois são "responsáveis pela minimização das enchentes a jusante através da fricção, efeito esponja e elevadas taxas de evapotranspiração; controle do assoreamento por reter sedimentos; fontes de matéria orgânica para peixes e demais organismos fluviais e habitat para espécies significativas". A vegetação dos fundos de vale, ao contrário de edifícios e pavimentação, "absorvem a energia solar e a utilizam em seus processos fisiológicos, formando áreas frescas dentro das cidades, contribuindo para amenizar as ilhas de calor" formadas por estes conforme Travassos e Grostein (2003). Segundo estudos desenvolvidos por Barros et al. (2003) e Zanini (1998), mais da metade dos fundos de vale da cidade de Londrina encontram-se desprovidos de vegetação. 
TRABAQUINI, K. et al. Uso e ocupação das APPs em áreas de fundo...

No presente estudo encontrou-se situação semelhante, sendo observado que somente uma pequena parte dos fundos de vale da cidade apresentam cobertura vegetal nativa.

Somente 388,2 ha ou $26,25 \%$ de APPs presente nos fundos de vale são ocupadas pela classe Florestal, esta classe deveria representar a maioria das áreas de fundo de vale. Mas, esta realidade pode ser explicada pelo intenso processo de urbanização que ocorreu nos últimos anos. Esta vegetação está concentrada na região sul da área urbana de Londrina, especificamente na bacia hidrográfica do Ribeirão Cafezal, a qual é responsável pelo fornecimento de água para aproximadamente $40 \%$ da população deste município, o que é favorável para a manutenção da qualidade da água. A característica do relevo desta área favoreceu a preservação da vegetação, já que alguns vales são mais encaixados dificultando $o$ acesso e retirada de madeira.

TABELA 2 - CLASSES DE USO E OCUPAÇÃO DOS FUNDOS DE VALE DA ÁREA URBANA DA CIDADE DE LONDRINA - 2007

\begin{tabular}{c|c|c}
\hline Classes de Uso e Ocupação & Área (ha) - 2007 & $\mathbf{\%}$ \\
\hline Florestal & 388,2 & 26,25 \\
\hline Arbórea & 365,1 & 24,69 \\
\hline Capoeira & 253,5 & 17,11 \\
\hline Rasteira & 316,4 & 21,38 \\
\hline Agrícola & 84,2 & 5,68 \\
\hline Urbano & 72,0 & 4,87 \\
\hline Total & 1.478 & 100 \\
\hline Área do perímetro urbano & 24.765 & - \\
\hline
\end{tabular}

Das seis classes, duas sofrem ação antrópica direta, que são as classes: Agrícola com 5,68\% e Urbano com $4,87 \%$. Estes dois tipos de ocupação podem ser considerados os mais críticos, pois acarretam em impactos ambientais muitas vezes irreversíveis para este ecossistema. A agricultura quando executada de forma inadequada é uma das fontes de poluição do solo e da água, pois a utilização de defensivos e insumos agrícolas em excesso pode vir a causar impactos sobre estas áreas de preservação. Do mesmo modo, a ocupação urbana também contribui para a degradação das áreas de APPs, sendo que estas áreas são ocupadas irregularmente por edificações na maioria dos casos. Segundo Barros et al. (2003), a "ocupação irregular destas áreas não ocorre apenas pela população de baixa renda, a qual, muitas vezes sem acesso a moradia, passa a ocupar áreas impróprias à habitação, mas são motivadas também pela aprovação indevida de loteamentos urbanos".

A vegetação Arbórea representa $24,69 \%$ da ocupação em APPs de fundo de vale. Caracterizada principalmente pela presença de árvores locadas sobre grandes extensões com gramíneas em seu substrato inferior, estas espécies passam a competir com as espécies nativas e a comprometer o estado de sucessão e a recuperação destas áreas quando em estado de degradação.
A vegetação Capoeira ocupa 253,5 ha, ou seja, $17,11 \%$ da área total. Esta categoria de vegetação é o estágio posterior à derrubada ou retirada das árvores de maior diâmetro, isto é, a transformação da área de mata em capoeira. Esta área é dominada pelo estrato arbustivo-arbóreo aberto, e a regeneração é afetada por variáveis antropogênicas, incluindo a escala do distúrbio e o uso da terra nos seus arredores, além de normalmente estarem localizadas em solos de maior dificuldade de trabalho.

A classe Rasteira é representada por 316,4 ou $21,38 \%$ da APPs, e é predominantemente ocupada por espécies herbáceas, normalmente gramíneas. A maioria destes locais é utilizada para pastagem na área rural, cuja utilidade está voltada à alimentação animal e na área urbana esta classe é utilizada para a recreação e lazer da população, como no caso do Lago Igapó, localizado no centro da cidade de Londrina.

\section{CONSIDERAÇÕES FINAIS}

A avaliação visual utilizando imagens de alta resolução espacial do satélite Quickbird com o auxílio da ferramenta de Sistema de Informação Geográfica - SIG, em destaque para o Geoprocessamento e Sensoriamento Remoto demonstrou ser de grande valia, 
TRABAQUINI, K. et al. Uso e ocupação das APPs em áreas de fundo...

pois foi possível avaliar e constatar o problema existente nas áreas de APPs de fundo de vale inseridas na área urbana de Londrina.

A classificação e a comparação entre as classes de ocupação, tanto em termos cartográficos quanto em tabelas analíticas, mostraram-se viáveis quando comparadas em porcentagens de ocupação, facilitando a compreensão e espacialização como foi apresentado neste trabalho. E ainda é possível constatar que as leis vigentes como o Código Florestal, lei federal $n^{\circ}$. 4.771/65 e o Plano Diretor do Município são suficientes para manter a preservação dos fundos de vale desde que a fiscalização seja realizada regularmente e de forma eficiente.

Neste mesmo contexto Mendonça e Barros
(2002) utilizaram imagens do sensor ETM com resolução espacial de 30 metros para avaliar os fundos de vale da área urbana de Londrina-PR. Observa-se que houve um pequeno avanço na classe Arbórea, já que no trabalho analisado em 2003 algumas áreas ocupadas pela vegetação Capoeira atualmente foram classificadas como arbórea, provável consequência de medidas de conservação e preservação realizadas pelo poder publico.

A avaliação das áreas de APPs de fundo de vale da área urbana de Londrina é um importante aspecto a ser abordado pelo Poder Público Municipal através da fiscalização de uso e ocupação do solo e do direcionamento de recursos para a preservação e conservação deste ambiente.

\section{REFERÊNCIAS}

BARROS, M. V. F.; SCOMPARIM, A.; KISH, C. S.; CAVIGLIONE, J. H.; ARANTES, M. R. L.; NAKASHIMA, S. Y.; REIS, T. E. S. Identificação das ocupações irregulares nos fundos de vale da cidade de Londrina-PR, por meio de imagem Landsat 7. RA'EGA, n. 7, Curitiba: UFPR, p. 47-54, 2003.

BRASIL. Código Florestal Lei n. 4.771 de 1965. Disponível em: <www.planalto.gov.br/ccivil_03/Leis/L4771.htm>. Acesso em: 17/10/2008.

BRASIL. Crimes Ambientais Lei n. 9.065 de 1998. Disponível em: <www.planalto.gov.br/ccivil_03/Leis/L9605.htm>. Acesso em: 17/10/2008.

EMBRAPA. Empresa Brasileira de Pesquisa Agropecuária. Disponível em: <www.sat.cnpm.embrapa.br/satelite/quickbird. $\mathrm{html}>$. Acesso em: 14/8/2008.

GREEN, K. The Potential and limitations of remote sensing and GIS in providing ecological information. In: SAMPLE, V. A. (Ed.). Remote sensing and GIS in ecosystem management. Washington: Island Press, 1994.

GUIMARÃES, I. M. P. S.; CANEPARO, S. C. Identificação de áreas adequadas à implantação de infra-estrutura arquitetônica através do uso do sistema de informação geográfica (SIG): estudo de caso - Parque Nacional Saint-Hilaire/Lange Paraná. RA'EGA, n. 14, Curitiba: UFPR, p. 67-83, 2007.
IBGE. Instituto Brasileiro de Geografia e Estatística. Manual técnico de uso da terra. 2. ed. Rio de Janeiro. 2006. 91p.

LONDRINA. Zoneamento de Uso e Ocupação do Solo Lei Municipal n. 7483 de 1998. Disponível em: <www2.cml.pr.gov. $\mathrm{br} / \mathrm{lnd} / \mathrm{index} \cdot \mathrm{html}>$. Acesso em: 21/11/2008.

MENDONÇA, L. B.; BARROS, M. V. F. Mapeamento da vegetação de fundo de vale da cidade de Londrina-PR, a partir de imagens ETM Landsat-7. Geografia: Revista do Departamento de Geociências, Londrina, v. 11, n. 1, jan./jun. p. 67-79, 2002.

PELLEGRINO, P. R. M. Pode-se planejar a paisagem? In: Paisagem e Ambiente Ensaios, n. 13, dez 2000. São Paulo: FAUUSP/Fapesp, 2000.

SEMA. Secretaria Municipal do Ambiente. O Rio da Minha Rua - uma experiência em Londrina-PR. Disponível em: <home. londrina.pr.gov.br/homenovo.php?opcso=oriodaminhrua\&item =artigo_riodaminharua $>$. Acesso em: 28/1/2009.

TRAVASSOS, L. R. F.; GROSTEIN, M. D. A ocupação de fundos de vale urbanos em São Paulo e sua dimensão sócioambiental. ENCONTRO NACIONAL DA ANPUR, 10., 2003, Belo Horizonte. Anais... Belo Horizonte., 2003

ZANINI, R. Espacialização do verde urbano em Londrina/ $P R$. Monografia (Bacharelado em Geografia) - Universidade Estadual de Londrina, Londrina. 1998. 
